\title{
THE IMPACT OF SOCIAL MEDIA CONSUMPTION ON CULTURAL INTELLIGENCE OF USER
}

\author{
Petra Zecevic, Lana Miletic and Ljerka Luic \\ University North, Trg dr. Zarka Dolinara 1, Koprivnica, Croatia
}

\begin{abstract}
With the digitalization and relocation of almost all human communications to the online sphere, social networks have gained great importance and room for maneuver for influence in the domain of lifelong learning. Enabling the rapid sharing of a large amount of information, ideas, but also content in general, has an impact on every user of these networks. This paper aims to show the impact of social networks, that is, the consumption of social networks, on the cultural intelligence of the individual. The subject of this paper was to determine which digital competencies, defined by information constructs Knowledge and Skills, significantly determine the level of cultural intelligence of an individual during his lifelong education, formal and informal, and the primary goal was to create a new information construct. The research was conducted online, using a survey questionnaire containing original metrics of influencing factors on the basis of which the application of quantitative statistical methods designed a conceptual model, a description that can determine the impact of each information construct (Knowledge, Skills, Experience) on digital intelligence development and its impact on degree of cultural intelligence. In this sense, this paper represents a contribution to the field of communication and educational sciences and opens initiatives for further research related to the development of an original methodology for conceptualizing digital communication in the field of non-formal education.
\end{abstract}

\section{KEYWORDS}

Digital Intelligence, Cultural Intelligence, Social Media, E-Education, Life-Long Learning

\section{INTRODUCTION}

Every day, thanks to global connectivity and technological advances, the individual has the opportunity to make countless contacts regardless of time and space. The networking of people leads to new situations in which it is no longer necessary to be physically present to communicate, which, consequently, leads to the possibility of communication with people from other countries, cultures, climates, and people with different life habits (Miladrovic, 2010). Increasing networking is influenced by an increasing number of social networks that allow virtual communication between two or more people, whether it is two-way or one-way communication. Social networks enable digital communication between people how to know or don't know each other, the exchange of messages between them, and their connection. And all the achieved communication, both in the real and virtual world, has an impact on the individual. Through social networks, people are allowed to present their opinions and thoughts, discuss political and social matters (Nakic, Sosic, Diklic, 2019).

For communication between people to be achievable (in the real or digital world), mutual understanding of communicators is important. It is necessary to overcome language barriers, but also different cultural situations that an individual need to be able to recognize to know how to behave in a particular situation, without creating additional problems. For an individual to be able to respond to any situation, it is important to have a pronounced cultural intelligence, whether or not cultural intelligence is meant like concept of mindfulness as a key component that links knowledge with behavioral capability (Thomas, 2006) or like a mediator between proactive personality and social adjustment (Hu, Liu, Zhang \& Wang, 2020). 


\section{LITERATURE REVIEW}

The history of the development of social networks coincides with the development of ICT and the Internet. The first prototype of social network was SixDegrees.com. It was created in 1997, and since then, social networks have become a global phenomenon (Kittinger 2012). According to its creator, A. Weinreich, the system was "ahead of its time," and therefore, unsustainable. It shut down in 2000 (Boyd and Ellison, 2007). The next wave of this global communication phenomenon begins with Ryze.com and it's social add-on Friendster (created in 2002) (Cohen, 2003). Unlike their predecessors on Friendster, users had the option to post photos in addition to their personal information (Boyd and Ellison, 2007). A large number of users and many fake profiles were crucial to Friendster because there was a software overload that engineers could no longer handle. To attract dissatisfied Friendster users, the social network MySpace was launched in 2003 and had features that other networks did not have: freedom of writing and an unlimited number of characters, the ability to customize profiles to user requirements, add music, etc. (Boyd and Ellison, 2007).

Facebook was initially developed and intended for university students (Kittinger, 2012), but quickly became available to anyone over the age of 13 who has their email address (Stern and Taylor, 2007). In 2005, it was the most visited website (Schwartz, 2012). Unlike hitherto popular networks, Facebook has developed new features so that users can better customize their profile (Cheung, Chill, Lee, 2011, according to Hill, 2014). Over the next two years, Facebook's numbers grew steadily, so it's no surprise that in 2007, it surpassed its competitor MySpace (Boyd and Ellison, 2007). Today, Facebook has 2.6 billion active users per month (Clement, 2020), making it the number one social network in the world.

Beside Facebook, Twitter and Instagram are social networks that are most often mentioned in both literature and the media world. The social network Twitter was launched in 2006 and today has 326 million users (Clement, 2020). It belongs to the so-called microblogging and, as such, allows easy sharing of messages (status) either publicly or within a social network. Unlike other social networks (Facebook, MySpace, etc.) on Twitter, a user's tracking does not necessarily have to be reciprocated (Huberman et al., 2019). In October 2010, Instagram was launched - a mobile application that allows users to turn their photos into visually appealing ones, which they then share with other users online (Soloman, 2013). Of course, Instagram's capabilities and features have changed in many ways since 2010, and today, this social network is the sixth in the number of users (1.1 billion) (Clement, 2020). It allows posting multiple photos in one post, saving pictures and videos, exchanging messages, various filters, and animations, and perhaps the most used feature so-called. "Instagram stories" - posting photos and / or videos in a row. Historically, Facebook, Twitter, and Instagram are the most famous social networks. But today, we can also talk about many others that gather more and more users every day. Facebook is still the most dominant social network; however, it is followed by Youtube ( 2 billion users), WhatsApp ( 2 billion users), Facebook Messenger (1.3 billion), and WeChat (1.2 billion). Twitter, once the most popular, now has only 326 million users (Clement, 2020).

Human is a social being who, from the beginning of his existence, seeks interaction with other people, with a tendency to create a community in which he will be able (with the direct or indirect support of all members) to realize his potential for the benefit of himself and his environment. Providing social support is one of the essential functions of social relations. Thus, the term social network refers to a system of social relations within which individuals may or may not provide social support and serve those functions that are not related to providing support (Ferlander, 2007). This notion of the human as a social being can be transferred to the digital world. If we talk and observe social networks from an IT perspective, the literature provides several definitions, but they all talk about social networks as tools for communicating with each other. Perhaps the most commonly used definition of social networks that appears in the literature is that given by Kaplan and Haenlein (2010), in which social networks are described as "group of Internet-based applications that build on the ideological and technological foundations of Web 2.0, and that allow the creation and exchange of User Generated Content. ".A more precise definition is given by Carr and Hayes (2015), according to which social networks are internet-based mass communication channels that enable interaction between users, gaining value primarily from user content. The same authors explain the given definition, stating that users can self-present through social networks, either in real-time or asynchronously (without defined time intervals), regardless of whether they present themselves and exchange information with a wider or narrow audience. 


\subsection{Cultural Intelligence}

Thanks to digitalization and communication in the online sphere, people's connection is the greatest in history. Given the trends, everyday innovations, and the expansion of the online sphere, we can only expect even greater connectivity between people, increasing online sharing of information, content, ideas, and influence. All of this sharing and interactions among people from different backgrounds, whether sharing in physical presence or not, affect human nature inseparable from culture (Cervone and Pervin, 2013).

This inseparability of culture from human nature is contained in cultural intelligence. There is no single definition, especially when one considers that there is no consensus among scientists and authors on what intelligence is and what intelligence types exist. Each of the communicators enters the communication from a particular starting point. When we consider that the communicators come from different cultures, then the cultural starting point is different among them. To understand the other side, to understand communication in its original, intended form, communicators need to have specific skills and competencies. When it comes to culture, strong cultural intelligence is required to understand others. As there is no single accepted definition of cultural intelligence, different authors have presented their cultural intelligence views. Thus, according to Thomas (2015), cultural intelligence is defined as an ability that enables effectiveness in intercultural interactions. Earley and Mosakowski (2004) describe cultural intelligence as the seemingly innate ability of each person to interpret the unknown and ambiguous gestures of members of another culture in the same way that people who are members of that culture would do so. Earley and Ang (Ang et al., 2007) are on the trail of this: cultural intelligence is the ability to adapt to new cultural contexts. But according to them, the concept of cultural intelligence is contained through four aspects: cognitive, metacognitive, motivational, and behavioral. The cognitive aspect is the specific knowledge that people acquire about a new culture while metacognitively making superior judgments that they make in their thought processes. A tendency to act on the cognitive aspect and the persistence in acquiring knowledge constitute the motivational aspect. In contrast, the behavioral aspect is the ability to carry out the desired or intended action.

Each of these authors confirms with his definition of cultural intelligence the theory of multiple intelligences, of which cultural is only one of the few that together build a person's intelligence. Also, the authors define cultural intelligence as an ability, and ability is measurable. Early and Mosakowski (2004) decided to measure the (under) development and (in) presence of cultural intelligence through the profiles of cultural intelligence they created. In their paper, they made a presentation on how to make a cultural intelligence profile and how to measure it. According to them, to arrive at a cultural intelligence profile, it is necessary to present to the respondent several statements from three different domains: cognitive, physical, and emotional/motivational.Each of these domains contains four predetermined statements to which the respondent gives grades from 1 to 5 , where 1 indicates complete disagreement, and 5 fully agrees with what has been said/written. Within each domain, the scores next to statements are added up and divided by four. The obtained figure is an indicator of the level of that part of cultural intelligence. The results of all three domains summed and divided by three give the final outcome of cultural intelligence. According to Earley and Mosakowski, a score of less than 3 shows a lack of cultural intelligence and the need to work on it (since cultural intelligence is defined as an ability, it is possible to reduce and increase it), while scores of more than 4.5 are satisfactory and show the presence of strong cultural intelligence.

\subsection{The Connection between Cultural Intelligence and Social Networks}

Following social-cognitive theories of personality, which is "based on the importance of learning by observation, and on the thought processes on which individual differences are based" (Penava Brekalo, 2010), social networks and cultural intelligence can be linked. Daily use, high exposure to different content, which includes various cultural situations that an individual witnesses through viewing content on social networks, and possibly a participant, if involved in a discussion or conversation with another party or sites that are different cultures, influencing the individual. Whether an individual uses social networks to inform, gain friends, or to stay in touch with existing friends and family, he is exposed to content that he is not primarily interested in, or is not yet aware that he is interested, but which captures his attention and, consequently, affect it. Social networks enable virtual reality or another life (Milardovic, 2010), a life in which everyone presents themselves in a certain way that may or may not correspond to the real situation in the actual reality. According to Milardovic (2010), social networks enable the disclosure of specific data due 
to a large amount of personal information that can be misused. The data found on social networks is the property of the social networks on which they are located, not the individual ones that relate. Due to that, a clear line of demarcation between the private and public is lost, and there is a possibility of manipulating this data.

Bilic (2020) stand out that social media users bring different values and features, including their cultural ones, into social media environment which makes it dynamic and similar to the physical environment and relations. That is the reason why social media connect social actors with connections of varying intensity.

Furthermore, according to Milardovic (2010), virtual friends are an oxymoron because friends are those, in reality, people to whom the individual is close, and in the possibility of making face-to-face contact. That is why the virtual social community, to which an individual can tend to or be a part of it, makes a paradox because it lacks real social connection. This leads to the fact that virtual friends in the real world are strangers: "The phenomenon of a stranger in society is as old as human society. This phenomenon in the social sense is the subject of phenomenological sociology. In modern society, strangers are members of other cultures who came to a society to stay. Today, in the age of globalization, more and more parties in societies are attractive as a society of accepting and founding a new life. In these societies, strangers are the "others" we encounter, tolerate, or avoid in our daily lives. By constructing artificial or virtual reality, we face a new phenomenon of a cyber stranger. Cyber or IC technology creates a new kind of virtual strangers. Techniques and technology in the anthropological sense do not only have the function of relief. They produce mutations, transformations, and new alienations. Cyberspace is a space of alienation. In cyberspace, man is a stranger to man. It is actually a space of strangers." (Milardovic, 2010). Guided by the fact that everyone is a stranger to social networks (if we take a smaller number of acquaintances and real friends with whom he intentionally communicates via a social network), it is essential to find out what impact they have on social networks, especially in terms of cultural intelligence. In this way, the cyberspace in which the users of social networks find themselves is seen as real situations, situations face to ear, in which there are people of different cultures. In cyberspace, it is an encounter without face-to-face communication, but it is still an encounter of different cultures and should be observed in this way.

\section{RESEARCH METHODOLOGY}

Based on the reviewed methodological literature, we conclude that the questionnaire, especially in the social sciences, is the essential measuring instrument for data collection. The questionnaire is used to survey public opinion and collect demographic, socioeconomic, and other informations of respondents (Mejovsek, M, 2013). Since this work was mostly aimed at social network users, it is natural to use an online questionnaire in which closed-ended questions were asked (respondents were offered an answer in advance), thus facilitating the statistical processing of the obtained data and their interpretation.

The questionnaire created for this paper is based on two previously used questionnaires in similar surveys. The first part examines the ways and frequency of social network consumption. This part was adapted from the questionnaire posted on research.net (NSE, 2020). The second part is based on Christopher Earley and Elaine Mosakowski's questionnaire (2004) to determine the cultural intelligence level. The questionnaire was distributed online, more specifically via Google Form posted on all current social networks and email addresses of respondents. In order to obtain the most diverse and wide range of the structure of the respondents, the sample was simple random. The research was nationally based: all respondents are from Croatia. The entire statistical analysis was made in the SPSS program.

For the purposes of the paper, the objectives of the research are defined:

- show the impact of social networks on the cultural intelligence of the individual

- determine which digital competencies determine the level of cultural intelligence of an individual

- create a new information construct

Accordingly, the paper hypothesizes are:

$\mathrm{H} 1$ : There is a positive correlation between social media consumption and cultural intelligence.

H1.1: There is a positive correlation between the greater use of social networks and cultural intelligence

H1.2: There is a positive correlation between the length of use of social networks and cultural intelligence 


\section{RESULTS AND DISCUSSIONS}

According to the obtained results, it can be concluded that all respondents use social networks, regardless of age and gender, and the largest number of respondents is aged 26 to 39 years. Equally, 137 female and 78 male respondents participated in the study. Comparing the age variable with the variable number of social networks that respondents use and the time they spend on them, we find that there is a significant negative correlation in both analyzes. In other words, the younger the respondents are active on more social networks, and the time they spend on social networks is longer compared to older age groups (Tables 1 and 2). According to the research results, it can be concluded that younger respondents have a higher degree of cultural intelligence; however, the correlation between these two variables is not significant (Table 3).

Table 1. Correlation between age and number of networks used by respondents

\begin{tabular}{llr|r}
\hline & & Number & \multicolumn{1}{c}{ Age } \\
\hline Number of & Pearson Correlation & 1 &,$- 316^{* *}$ \\
soc. netw. & Sig. (2-tailed) & &, 000 \\
& $\mathrm{~N}$ & 215 & 215 \\
\hline Age & Pearson Correlation &,$- 316^{* *}$ & 1 \\
& Sig. (2-tailed) &, 000 & \\
& $\mathrm{~N}$ & 215 & 215 \\
\hline
\end{tabular}

Table 2. Correlation between age and time that respondents spend on network

\begin{tabular}{llr|r}
\hline & & \multicolumn{1}{c|}{ Age } & \multicolumn{1}{c}{ Time } \\
\hline Age & Pearson Correlation & 1 &,$- 260^{* *}$ \\
& Sig. (2-tailed) & &, 000 \\
& N & 215 & 215 \\
\hline Time spent & Pearson Correlation &,$- 260^{* *}$ & 1 \\
on soc.netw & Sig. (2-tailed) &, 000 & \\
& N & 215 & 215 \\
\hline
\end{tabular}

Table 3. Correlation between age and and cultural intelligence

\begin{tabular}{llr|r}
\hline & & Age & \multicolumn{1}{c}{ CQ } \\
\hline Age & Pearson Correlation & 1 &,- 021 \\
& Sig. (2-tailed) & &, 755 \\
& $\mathrm{~N}$ & 215 & 215 \\
\hline CQ & Pearson Correlation &,- 021 & 1 \\
& Sig. (2-tailed) &, 755 & \\
& N & 215 & 215 \\
\hline
\end{tabular}

When comparing the gender variable with the number of social networks used by the respondents and the time, they spend on them, the research results show that there is a positive correlation. Still, it is not significant (Tables 4 and 5). The situation is similar if we compare the gender variable with the cultural intelligence level variable (Table 6).

Table 4. Correlation between gender and and number of networks used by respondents

\begin{tabular}{llr|r}
\hline & & Gender & \multicolumn{1}{c}{ Number } \\
\hline Gender & Pearson Correlation & 1 &, 068 \\
& Sig. (2-tailed) & &, 323 \\
& N & 215 & 215 \\
\hline Number of & Pearson Correlation &, 068 & 1 \\
soc. netw. & Sig. (2-tailed) &, 323 & \\
& N & 215 & 215 \\
\hline
\end{tabular}


Table 5. Correlation between gender and and time that respondents spend on network

\begin{tabular}{|c|c|c|c|}
\hline & & Gender & Time \\
\hline \multirow[t]{3}{*}{ Gender } & Pearson Correlation & 1 & 085 \\
\hline & Sig. (2-tailed) & & 214 \\
\hline & $\mathrm{N}$ & 215 & 215 \\
\hline \multirow{3}{*}{$\begin{array}{l}\text { Time spent } \\
\text { on soc. netw. }\end{array}$} & Pearson Correlation & 085 & 1 \\
\hline & Sig. (2-tailed) & ,214 & \\
\hline & $\mathrm{N}$ & 215 & 215 \\
\hline
\end{tabular}

Table 6. Correlation between gender and cultural intelligence

\begin{tabular}{llrll}
\hline & & CQ & & Gender \\
\hline CQ & Pearson Correlation & 1 & CQ \\
& Sig. (2-tailed) & & \\
& N & 215 & \\
\hline \multirow{2}{*}{ Gender } & Pearson Correlation &,- 019 & Gender \\
& Sig. (2-tailed) &, 783 & \\
& N & 215 & \\
\hline
\end{tabular}

In the analysis of given hypotheses and sub-hypotheses, we do not come to significant results. According to the obtained results, it is evident that there is a tiny positive correlation between the consumption of social networks (whether it is the number of social networks or the time spent on them) (0.128 and 0.059). In other words, we can conclude that the given hypothesis is confirmed in this paper, but not significantly. The results are shown in Tables 7 and 8 .

Table 7. Correlation between cultural intelligence and and number of networks used by respondents

\begin{tabular}{llr|r}
\hline & & CQ & \multicolumn{1}{c}{ Number } \\
\hline CQ & Pearson Correlation & 1 &, 128 \\
& Sig. (2-tailed) & &, 062 \\
& N & 215 & 215 \\
\hline Number of & Pearson Correlation &, 128 & 1 \\
soc. netw. & Sig. (2-tailed) &, 062 & \\
& N & 215 & 215 \\
\hline
\end{tabular}

Table 8. Correlation between cultural intelligence and time that respondents spend on network

\begin{tabular}{llr|r}
\hline & & CQ & \multicolumn{1}{c}{ Time } \\
\hline \multirow{2}{*}{ CQ } & Pearson Correlation & 1 &, 059 \\
& Sig. (2-tailed) & &, 390 \\
& N & 215 & 215 \\
\hline \multirow{2}{*}{ Time spent } & Pearson Correlation &, 059 & 1 \\
on soc. netw. & Sig. (2-tailed) &, 390 & \\
\hline
\end{tabular}

The reason for such results can be found in the following three facts; first of all, the research was conducted on a small sample, and it is to be assumed that a larger sample of respondents would give more significant results. Likewise, although the survey was anonymous, it is about questioning the respondents' attitudes towards other cultures members. Such questions are always sociologically sensitive, and it may happen that respondents do not give honest answers, but answers that they think are socially acceptable and desirable. The third reason can be related to ignorance or misunderstanding of the concept of cultural intelligence. 


\section{CONCLUSION}

Although this research results are not statistically significant, this paper shows us that with the increase in the number of social networks used by the respondent and with the longer time spent on them, the level of cultural intelligence increases. This conclusion is not too surprising if we consider that the largest percentage of respondents belong to the so-called Generation Y age group.

Although they are not digital natives (as their followers, generation Z), they have been very familiar with the Internet and social networks since their teenage years, which have greatly influenced their attitudes towards society. Furthermore, this generation has grown up in an age of significant social change and is much more tolerant and socially vulnerable. This research only scratches the surface of the problems of today's global phenomenon of social networks and their impact on the behavior of the individual in different cultural communities than the one in which he lives.

For a deeper and more adequate analysis, it would be desirable to do research that would enter the online world and look at those respondents who do not use social networks. In this way, a more detailed comparison of the users and non-user behavior of social networks in the context of their cultural intelligence could be made. Furthermore, this research is only a presentation of "theoretical answers" that may not be consistent with the behavior that would occur if a person were indeed in a multicultural situation/environment. Therefore, it is necessary to research focus groups (after a questionnaire examines the respondents) and see how similar our ideas are about how tolerant we are and what level of cultural intelligence we possess with the real situation in real-time.

\section{ACKNOWLEDGEMENT}

Publication of this paper was supported by mentors and $\mathrm{PhD}$ students grant from the University North to which the authors of this article are grateful for the big support.

\section{REFERENCES}

Ang, S. ... [et al]. 2007. Cultural Intelligence: Its Measurement and Effects on Cultural Judgment and Decision Making, Cultural Adaptation and Task Performance. Management and Organization Review, 3(3), 335-371. doi:10.1111/j.1740-8784.2007.00082.x

Bilic, P. 2020. Sociology of media: routines, technology and power. Zagreb: Naklada Jesenski i Turk

Boyd, D. M., \& Ellison, N. B. 2007. Social network sites: Definition, history, and scholarship. Journal of computer-mediated communication, 13(1), 210-230. URL: https://onlinelibrary.wiley.com/doi/pdf/10.1111/j.10836101.2007.00393.x (accessed: 15.9.2020)

Celment, J. 2020. Global social networks ranked by number of users 2020. Statista. August 21, URL; https://www.statista.com/statistics/272014/global-social-networks-ranked-by-number-of-users/ (accessed: 23.9.2020)

Cervone D., Pervin L.A. 2013. Personality: Theory and Research (12. edition). SAD: Wiley

Cohen, R. 2003. Livewire: Web Sites Try to Make Internet Dating Less Creepy, July 5, URL: http://www.zephoria.org/thoughts/archives/2003/07/05/livewire_web_sites_try_to_make_internet_dating_less_creep y.html (accessed: 27.9.2020)

Diklic, J., Nakic, M., Sosic, D. 2019. Educational role of social networks in child media education, Communication Management Review, 04(01), str. 178-195. https://doi.org/10.22522/cmr20190146

Earley, P. C., Mosakowski, E. 2004. Cultural Intelligence, Harvard Business Review, https://hbr.org/2004/10/culturalintelligence (accessed: 1.9.2020)

Ferlander, S. 2007. The Importance of Different Forms of Social Capital for Health. Acta Sociologica, 50(2), 115-128. Retrieved September 28, 2020, from http://www.jstor.org/stable/20459987 (accessed: 27.9.2020)

Goltnik Urnaut, A. 2014. 'Education for successful intercultural communication and cultural intelligence', Journal of economic and social developmen, 1(1), str. 63-73. URL: https://hrcak.srce.hr/128529 (accessed: 1.9.2020) 
Hayes, R. A. 2015. Social Media: Defining, Developing, and Divining Caleb T. Carr, Ph. D. School of Communication Illinois State University 456 Fell Hall, Campus Box 4480, Illinois State University, N ormal, IL 61790-4880 USA. Atlantic Journal of Communication, 23, 1. URL: https://my.ilstu.edu/ ctcarr/research/CarrHayes_2015.pdf (accessed: 27. 9.2020)

Hill, C.L. 2014. An investigation of the connections between use of Facebook and the self-esteem/ well-being of students with disabilities in the University of Iowa Reach Program. PhD (Doctor of Philosophy) thesis, University of Iowa, URL: https://doi.org/10.17077/etd.5fxjx7dz (accessed: 15.9.2020)

Hu, S., Gu, J., \& Zhang, S. 2017. Social media usage, self-efficacy and cultural intelligence: A longitudinal empirical research in China. In Wuhan International Conference on e-Business. Association for Information Systems.

Hu, S., Liu, H., Zhang, S., \& Wang, G. (2020). Proactive personality and cross-cultural adjustment: Roles of social media usage and cultural intelligence. International Journal of Intercultural Relations, 74, 42-57.

Huberman, B. A., Romero, D. M., \& Wu, F. (2008). Social networks that matter: Twitter under the microscope. arXiv preprint arXiv:0812.1045. URL: https://www.researchgate.net/publication/23573983_Social_Networks _that_Matter_Twitter_Under_the_Microscope (accessed: 15.9.2020)

Kaplan, A. M., \& Haenlein, M. 2010. Users of the world, unite! The challenges and opportunities of Social Media. Business horizons, 53(1), 59-68. URL: https://www.researchgate.net/publication/222403703 _Users_of_the_World_Unite_The_Challenges_and_Opportunities_of_Social_Media (accessed: 27.9.2020)

Kittinger, R., Correia, C. J., \& Irons, J. G. 2012. Relationship between Facebook use and problematic Internet use among college students. Cyberpsychology, Behavior, and Social Networking, 15(6), 324-327.URL: https://www.researchgate.net/publication/227162158_Relationship_Between_Facebook_Use_and_Problematic_Inter net_Use_Among_College_Students (accessed: 15.9.2020)

Liao Y., Thomas D.C. 2020. Conceptualizing Cultural Intelligence. In: Cultural Intelligence in the World of Work. Springer Series in Emerging Cultural Perspectives in Work, Organizational, and Personnel Studies. Springer, Cham

Mejovsek, M. 2013. Scientific research methods in social sciences. Jastrebarsko: Naklada Slap

Milardovic, A. 2010. Global Village. Zagreb: Center for Political Science Research.

Nakic, M., Sosic, D., Diklic, J. (2019). 'INFLUENCE OF SOCIAL NETWORKS ON CIVIC ACTIVISM AND DEVELOPMENT OF CIVIC SOCIETY', South Eastern European Journal of Communication, I(1), str. 105-105. https://hrcak.srce.hr/233063 (Accessed: 26.10.2020)

NSE. 2020. 'Media Consumption Behavior'. https://www.research.net/r/interestmedia (Accessed: 26.6.2020)

Paska, I. (2019). 'Digital Media Environments and their Implications: Instagram', In medias res, 8(15), str. 2347-2364. https://hrcak.srce.hr/225457 (Accessed: 26.10.2020)

Penava Brekalo, Z. 2010. The Social Cognitive Theory of Personality in the Context of Personal Marketing. Ekonomski vjesnik/ Econviews: Review of Contemporary Entrepreneurship, Business, and Economic Issues, 23(1), 240-246.

Salomon, D. 2013. Moving on from Facebook: Using Instagram to connect with undergraduates and engage in teaching and learning. College \& Research Libraries News, 74(8), 408-412. URL: https://www.researchgate.net/publication/275043870_Moving_on_from_Facebook_Using_Instagram _to_Connect_with_Undergraduates_and_Engage_in_Teaching_and_Learning (accessed: 21.9.2020)

Schwartz, S. 2012. Does Facebook Influence Well-Being and Self-Esteem Among Early Adolescents?. URL: https://sophia.stkate.edu/cgi/viewcontent.cgi?article=1091\&context=msw_papers (accessed: 22.9.2020)

Stern, L. A., \& Taylor, K. 2007. Social networking on Facebook. Journal of the Communication, Speech \& Theatre Association of North Dakota, 20(2007), 9-20.

Thomas, D. C. (2006) 'Domain and Development of Cultural Intelligence: The Importance of Mindfulness', Group \& Organization Management, 31(1), pp. 78-99. doi: 10.1177/1059601105275266.

Zlof, K., Herljevic, Z., \& Hadzic, S. (2014). Journalists' perception of the importance of social networks in the production of media contents', Media, culture and public relations, 5(1), 17-29. https://hrcak.srce.hr/122433 (Accessed: 26.10.2020) 